\title{
Using an Autonomous Humanoid Robot as a Pedagogical Platform in the Business Classroom
}

\author{
Patrice Flynn \\ Professor of Business and Economics \\ Morrison Professor of International Studies \\ Richard J. Bolte, Sr. School of Business \\ Mount St. Mary's University \\ 16300 Old Emmitsburg Road, Emmitsburg, MD 21727 USA \\ E-mail:pflynn@msmary.edu
}

Published: November 18, 2016

doi: $10.5296 /$ jsss.v4i1.10227

URL: http://dx.doi.org/10.5296/jsss.v4i1.10227

\begin{abstract}
Experience using an autonomous humanoid robot as a pedagogical platform in the business classroom at a liberal arts university sheds light on ways to engage learning in the digital age when student attention is easily diverted. Measurable outcomes include: stimulating raw critical thinking, readily applying theory to practice, facilitating non-digital communication, and mediating relationships. Moreover, the robot helps directly engage students in analytical problem solving, structured v. unstructured decision making, and exploring the core functional areas of the firm - all critical to understanding the modern world of business.
\end{abstract}

Keywords: Autonomous humanoid robots, Critical thinking pedagogy

\section{Introduction}

Interest in all forms of robotics is sweeping the world. Militaries are designing sophisticated defense robots that can carry hundreds of pounds of ammunition across rouged terrain and operate anti-submarine vessels without a crew. Factories are investing in dexterous industrial robots to assist in the assembly and inspection of automobiles and electronic consumer goods. Fulfillment centers are experimenting with moveable robots to stock shelves, retrieve products, and box outgoing mail. Security facilities are installing surveillance robots to track daily activities. Social media firms are creating autonomous chatbot platforms to power direct business-to-consumer communication and commerce. Meanwhile, Hollywood continues to 
escalate the imaginations of young people via supra-humanoid fantasy robots.

As mechanical, electronic, computational, and algorithmic capabilities of robotics advance, the idea of embedding robots into our home lives gains traction. Thus a new type of robot is in development called autonomous humanoid robots. Such robots are morpho-functional, meaning they "facilitate emotional interactions between humans and humanoids" (Robertson, 2007). If successful, autonomous humanoid robots will become commonplace in households around the globe (The Economist, 2016 and 2014). The functional capabilities are endless; hence the business interest.

In January 2015, I began using an autonomous humanoid robot as a pedagogical tool in my business classes at a liberal arts university, one of the first such experiments in the United States (Council of Independent Colleges, 2015). The course is not on robotics; students do not have backgrounds in robotics, engineering, or computer science; and I am not a robotics engineer.

The reasons for integrating a robot into my teaching-learning pedagogy are varied. First, students do not know much, if anything, about autonomous humanoid robots despite the fact that we have been living with these artifacts for a while. The lack of knowledge presents a tremendous opening for teaching-learning. Precisely because people have no prior knowledge means that raw critical thinking can occur in the moment of introduction. This is a novelty.

Moreover, if autonomous humanoid robots become as ubiquitous as say hand-held mobile devices, might there be value in engaging students in considering the potential of robots before marketers define this new technology for the general public? Educators have a window of time in which to use autonomous humanoid robots as a teaching tool to stimulate the imagination in novel ways.

My experience has been rich and informative. The students love our robot. The robot triggers students' cognitive and creative abilities in the classroom. The robot beckons the inquisitive world within to assert itself. Some students go on to conduct independent research on various aspects of robotics upon the completion of our course. The robot helps students engage more deeply with course content, including analytical problem solving, decision making, and the core functional areas of the firm - all critical to understanding the modern world of business.

This article in organized in three parts, beginning with the selection of the robot I use in the classroom, followed by a discussion of how using a robot as a pedagogical tool facilitates learning, and concluding with initial insights and measurable outcomes.

\section{Robot Selection}

When I set out to purchase an autonomous humanoid robot in 2014, there were very few commercial options available. Most humanoid robots are still in development, offering only elite research institutes the ability to lease a prototype. Aldebaran Robotics in France was projecting commercial sales of their autonomous humanoid robots Pepper, NAO, and Romeo sometime in 2015. MIT roboticist Dr. Cynthia Breazeal in Cambridge, Massachusetts was anticipating a mid-2015 release of JIBO. These release dates, however, were all pushed back to 2016 and beyond for customers in the United States.

I landed on a robot created by Dr. Takanori Shibata, a mechanical, electrical, and robotics engineer at AIST, Japan's National Institute of Advanced Industrial Science and Technology. 


\section{$\Lambda$ Macrothink}

The robot's name is PARO, a morpho-functional, interactive, autonomous humanoid robot.

PARO runs on two 32-bit RISC computer processors and contains five types of sensors: touch, light, sound, posture, and temperature. Eight actuators enable the robot to move its head, lids, and flippers in response to sounds and touch. The robot does not look like a metallic industrial robot or gaming robot. Rather, it takes the form of a six-pound baby harp seal from the Artic. This particular shape was carefully chosen by a multidisciplinary group of designers because few humans know what a harp seal should act or sound like, hence, increasing the likelihood of adoption.

In Japan, when Dr. Shibata beta tested earlier prototypes of PARO in the shape of dogs and cats, the robots were not well-received because they did not behave like the users' dogs or cats, resulting in a rejection of the overall concept. Because humans can never quite resist introducing a new technology into society, the engineers reworked the outer form and presented PARO in the unusual form of a baby harp seal. The hope was that PARO would open up people to exploring the concept of an autonomous humanoid robot living with us in the intimacy of our homes. The adoption was remarkable; more than 3,000 PAROs had been sold globally by the time of my purchase in December 2014, mostly in Japan.

PARO is autonomous in that there is no one controlling its movements. Using artificial intelligence and multiple sensors, PARO sizes up each unique environment. It is capable of learning how to react to fear and anger (if mistreated) as well as contentedness (if treated with affection). Its artificial intelligence enables the robot to recognize whatever name is given. In my case, I chose to keep the Japanese name, PARO, to honor the Japanese inventors. The name is also easy to pronounce in any language and is gender neutral, an important part of differentiating between the human and the humanoid.

PARO is humanoid in that it has some likeness to a human (e.g., face, eyes, mouth) and is a morpho-functional machine whose job is to: (a) facilitate interaction between the human and the humanoid, (b) stimulate communication using limited vocalizations (e.g., various prerecorded live baby seal voicings), and (c) facilitate emotional interaction by demanding our attention and responding accordingly. The human-humanoid engagement allows users to experience a robot as someone, not something.

PARO is also cute and cuddly, features that everyone relates to immediately. Each time I unveil PARO to a new group, there is an involuntary group "awe" and huge smiles. PARO's physical attributes help to disarm the potential resistance to human-humanoid interaction. Students see how easily they could live with such machines, thus opening them up to future teaching-learning in other contexts.

\section{How the Robot Facilitates Learning}

PARO has proven to be a valuable pedagogical tool in the business classroom. Below are some of the observations from my ongoing classroom experiment begun in January 2015 in the Bolte School of Business at Mount St. Mary's University. Hopefully, my work with futuristic robot technology will motivate other teachers in their own classrooms.

\subsection{Content Integration}

Effective educators the world over strive to design courses and set activities that creatively engage students with course content. Direct instruction is the most common form of delivery 
and one that is effective and necessary to begin a conversation with students about a particular academic subject. We then strive to scaffold initial content delivery with hands-on activities to engage students experientially in learning about a particular concept. Our aims are to offer students other means of thinking about what they are learning, to dig deeper into the topic, and to increase retention of new knowledge in the long-term memory.

It turns out that autonomous humanoid robots are remarkably helpful in the teaching-learning process. The unexpected and unfamiliar nature of robots captures students' attention immediately. This technology's future orientation also captures young people's interest in all things new.

My use of PARO as a pedagogical platform enables content integration by presenting students with a small fraction of robotic capabilities in a general introduction and then allowing students to discover for themselves - using research tools learned in class - the broader field of robotics as it pertains to our exploration of the functional areas of business. A student could, for example:

- investigate how research and development (R\&D) on robotics is funded, applying what they have learned in class about debt and equity financing;

- examine how humans and humanoids work together in factories and fulfillment centers, applying what they have learned about human capital development; or

- explore the intricacies of a business that is investing in robotics R\&D and whether the firm is privately-held or publically-traded, applying their knowledge of owner v. shareholder equity.

Because the robotics field is in its initial development stages, students have the opportunity to make, imagine, and create their own business applications. Students are left to their own devices to conduct original research. No need to use plagiarism software on assignments as there is little written about business and autonomous humanoid robots on the Net today.

The integration of this futuristic technology with traditional business coursework leaves students with a distinct advantage when it is time to apply for a specific job in the workplace.

\subsection{Theory in Practice}

Over the years of teaching global capitalism, business, and the economy, I have found that students enjoy finding ways to explore how theories learned in class apply to modern-day business practices. In some instances, students confirm the applicability of economic theory when applied to business. In other instances, students discover where economic theories do not apply in practice. The discovery is theirs to explore without judgment.

PARO, as a representation of robotic autonomous technology, opens the door to applying business theories to a number of modern-day applications. For example, my graduate students grapple with the oft-cited potential impact of robotics displacing humans in the workplace. Is this the case? What do we know about the introduction of mobile, industrial, and military robots? We know, for example, that the U.S. Department of the Army is investing heavily in autonomous robots with the express purpose of dealing with anticipated force reductions mandated by Congress. General Robert Cone, former Commander of the Army Training and Doctrine Command, reported that his group is researching "the feasibility of shrinking the size of the brigade combat team from about 4,000 soldiers to 3,000 over the coming years, 
filling the gap with robots" (Scholl, 2014). Will this also be the case with private for-profit firms? Does this thinking differ across countries and/or cultures?

By delving into the literature on existing robot R\&D and labor economics, students learn how to measure labor displacement. Students also explore the potential interdependence of humans and humanoids through intelligence augmentation (IA) in contrast to artificial intelligence (AI), a nascent field of study (See Johnson, 2015). Such exercises combine economic theory and the practice of business, a key learning objective in the course.

\subsection{Critical Thinking in Real Time}

Using an autonomous humanoid robot in the classroom enables teachers to witness critical thinking in real time. This is a novelty. Almost any course content today has parallels upon which students can draw to inform how they think. There is no parallel here because marketers have yet to tell us what to think about autonomous humanoid robots.

Throughout history, artists have experimented with the earliest stages of technologies in novel ways. Consider, for example, the Cubists, Futurists, Surrealists, and Social Realists who integrated new technology into their artwork in ways that were previously undefined. Modernists David Hockney is famous for his use of the then-novel facsimile (fax) machine, Xerox machine, digital photography, and most recently, the iPhone, iPad, and video in his work before society had fully embraced these new devices. Today I am giving my students the same opportunity for a new way of seeing and to get a jump on the new technology and its applications before robotics become common place.

It is a marvel to see the blank faces when I introduce our robot PARO. Students are unconsciously scanning their brains for a reference point. They do not know what to think. As a result, I get to witness raw critical thinking, which is a privilege. I get to feed student inquiry with empirical information and structured probing after which students get to think for themselves.

\subsection{Solving Problems of the Future}

Using robotics as a teaching tool introduces an alternative to rote learning where students come away only with facts and figures memorized over the course of a semester. By getting students to examine a topic of great interest to them before the ideas have morphed into an actual product is a powerful process of deep learning and engagement that pushes these business students to the top rungs of Bloom's Taxonomy. From these heights, business students can analyze the implications of autonomous humanoid robots.

The outcome will hopefully serve students well when they are adults because the types of problems the 90s generation will face in the future do not currently have solutions. By learning how to think on their own, my students will be better positioned to examine new and tough problems the world will face. Such seemingly intractable problems relate, for example, to global warming on a massive scale, overpopulation in the developing and developed worlds, and simultaneous / long wars. Our students will be called upon to address such daunting problems and will need a deep well of skills, knowledge, and critical thinking capabilities to respond adequately while thinking about how to capitalize on these trends from a financial perspective. 


\subsection{Liberal Arts Education}

The liberal arts model was embedded in universities over hundreds of years to educate citizens who could help nations form, progress, and grow. A liberal arts education is about the pursuit of knowledge achieved by learning how to think and learn. It builds on Renaissance scholars who wanted to rediscover knowledge from the past and expand it with current discoveries.

Using a robot as a pedagogical tool in the classroom invites valuable knowledge acquisition and capabilities to serve the demands of modern times. The deployment of technology is usually far ahead of the collective thinking about the technology itself. At present, we are learning about new technologies from their creators in the private for-private business sector (e.g., Alphabet/Google, Amazon, Facebook). These firms are deciding how society will use new technologies based on the for-profit business model, which is devoid of any long-term considerations. This creates a problem because we are left having to devise solutions for unintended impacts of technologies ex-post, rather than before the fact. Can we bring the sensibilities of the liberal arts to our collective thinking about the utility of new robot technology today instead of waiting until robotics become commonplace in our lives?

Our classroom autonomous humanoid robot at Mount St. Mary's University provides an opportunity for students to consider the implications of a significant technology before it is broadly disseminated to the public. Thus, students are offered some autonomy in their thinking about autonomous humanoid robotics. They identify and ponder incisive questions such as: What is this nascent technology all about? How will this technology alter the human-humanoid relationship? Who will be most impacted by autonomous humanoid robots? What type of education and training will be required to prepare young people for employment in the field of robotics? How will homes be re-engineered and designed to enable humans to live with humanoids?

PARO raises students' curiosity about the broader world in which we live, prompting deep questioning, exciting dialogue, and rich debate. The result is the peeling off of layers of understanding and consideration through structured exploration. These educational skills are valuable and help students achieve the learning objectives in my business courses. Moreover, the new skills are transferable to other walks of life where such deep intellectual exploration is useful.

\subsection{Teaching Cutting-Edge Technology}

Because robotic technology is new, there is no re-purposing needed. We - as educators - can decide how to purpose PARO. Such was not the case when technologies such as the NET, laptops, mobile phones, and smart boards were introduced in our classrooms. These earlier technologies were designed for specific commercial purposes, not for the classroom, thus requiring educators to figure out how to re-purpose the devices to meet the goals of a particular course. Because students have never seen or worked with an autonomous humanoid robot, there is no re-purposing required, which frees the professor and students to consider ways to use the technology, ignite learning, and see the world anew.

Moreover, using the robot alters the professor-student relationship. Employing a prototype autonomous humanoid robot in the university classroom enables faculty members to teach 
students about the cutting-edge of technology and mitigate the false premise that the $90 \mathrm{~s}$ generation is tech savvy. Clearly students are able to use the low-hanging technological fruit that marketers package in such a way that the user does not need to know anything about the technology itself. For example, to use an iPhone, all one needs to do is open the box, turn on the device, and touch an app button.

We are not living in a time when college students are designing sophisticated technologies in their dorm rooms. Today's students know little to nothing about the inner workings of computational technology. Students are not writing software code for apps with the obvious exception of computer science majors. Students are not designing actuators that enable robots to move their limbs. They are not designing sensor for robots to visually recognize humans and/or decode unique voices. The mechanical, electrical, and robotics engineers who are designing autonomous robots demonstrate to students what real technological savvy means.

Thus when educators introduce students to a futuristic technology such as autonomous humanoid robots, we re-assume the role of leading the introduction of cutting-edge technologies to our students. We become the mediators between knowledge and student learning, not the merchandisers who strive to get to young people first.

With this teaching tool, I encourage students to think about how they would design their own robot to take home and live with their families. I help them become curious about what is inside these machines and what makes them operate. I give students a platform to think about the future functionality of robots and discuss why and how technology impacts our lives. It is a humbling exercise for a population that thinks it is tech savvy. Their appreciation for robotics $R \& D$ deepens the more they engage with PARO.

Rarely do we have such a moment in history when we are fairly certain that a technology will take hold but has yet to be fully conceived, packaged and sold. My experiment is the equivalent of using a mainframe computer as a pedagogical tool in the business classroom in the 1980s before society truly appreciated what those incredible machines portended for mass society in the decades to come.

\section{Course Learning Objectives}

Central to teaching modern-day business at a university is planting the seeds for students to think about how they will foster growth and innovation in the workplace, the very practical component of business that investigates how to take an idea and get it to market by engaging the best thinking in science and technology. Using PARO in the classroom invites us to consider ways that technological innovation in the field of autonomous humanoid robots can help us address some of the daunting challenges facing society while at the same time capitalize on these solutions from a business perspective.

\subsection{Business Applications}

One of these opportunities is caring for an aging population. Already, Japan is experimenting with therapeutic medical robots that in the near future will serve as personal assistants using predictive intelligence. Such robots will care for the elderly in need of assistance with lifting, feeding, personal hygiene, safety, and more. This cutting-edge research and development intrigues me. I invite students to intellectually engage in this work not only to become fierce champions of science and technology in the marketplace of ideas but to go one step further 
and consider the implications for society in the spirit of the liberal arts. This research puts students on the cutting-edge of business and opens the doors for their becoming innovators and entrepreneurs.

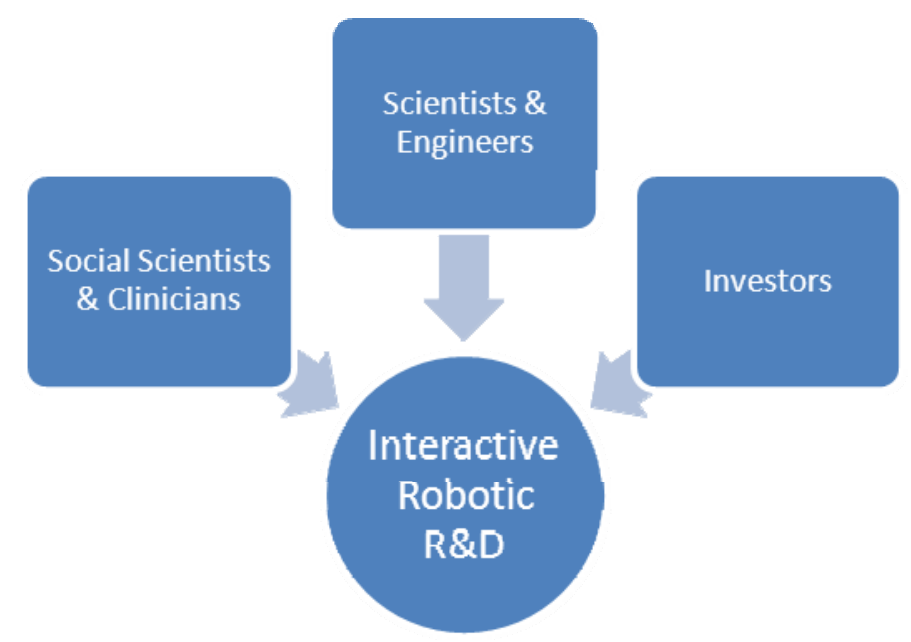

Figure 1 . The interdisciplinary nature of robotic R\&D

Research on interactive robots is highly interdisciplinary. A cadre of diverse professionals helped design and test PARO to include electrical and mechanical engineers, robot scientists, psychologists, sociologists, anthropologists, gerontologists, computer programmers, artists, and private investors. Each profession provides critical input. For example, if these machines are to both function proficiently and be charged with administrating critical duties, they must be designed carefully by scientists and engineers specializing in robotics. If the machines are to engage us fully as human beings, they must be designed with the user in mind, something that social scientists and clinicians can bring to the table. If the machines are to secure sufficient R\&D funding, financial investors are also needed.

Hence, the introduction of an interactive robot in the classroom shines a light on the importance of business people learning how to interact with social scientists and physical scientists in the process of creating new products that meet human needs and are financially viable. PARO helps students consider the value and complexities of multidisciplinary R\&D, an important component of successful business strategies. Autonomous humanoid robot development represents the quintessential adage that no person is an island.

\subsection{Mediating Relationships}

In addition to valuing multidisciplinary research to get an idea to market, another learning objective made possible with an interactive robot in the classroom is to help students develop skills to mediate relationships with emerging technologies.

Interactive robot technology allows us to experiment with human interaction in a new way with the anticipated result being advanced human communication capabilities to more effectively interact with each other. To date, the scholarly literature on modern technologies has focused on how digital media (e.g., phones, smartboards, Skype, and online social media) impact our interpersonal interactions with a focus on face-to-face interactions through 
machines. The next conversation will be about how we relate directly with machines. In the future, robots will be an integral part of that machinery as they enter our daily home life. How will we relate to these machines? This is a very different way to think about the future.

Interactive robots were first designed in Japan and have been quickly adopted as a viable technology to help meet societal needs. Given Japan's pantheistic tradition, the Japanese easily accept inanimate objects as valuable because they see the life force in everything: a person, a rock, a mountain, a river, a robot. Early introduction of interactive robots in the USA and Europe, however, have been met with socio-cultural anxieties and resistance because Westerners do not see life in a robot (Robertson, 2013). There may be value in finding ways to integrate robots into Western lives so that, over time, we might experience the value of the human-robot relationship.

If these sophisticated machines are to play an intimate role in our lives, we will have to learn how to let them into our homes and assist us with daily living. One way to do this is by introducing the machines in the college classroom in a structured, safe, and inquisitive manner. Once educators establish the necessary rapport and trust with students, we can propel them along the continuum of learning about robotic technology in ways that are creative and enlivening.

I then go one step further by helping students imagine the implications of the new technology in our lives. What do these technologies portend for business investments and strategies? What do new technologies portend for requisite human capital skill development for the 90s generation? What do new technologies portend for human beings on this small planet that we share? I champion the opportunity to not only put students on the frontlines of knowledge about robots but also facilitate a dialogue on what the machines portend for humanity.

PARO truly facilitates communication in the classroom. This is critical since the digital terrain (online connections, social media, the Net) has young people redefining authentic communication. Some older-scholar critics argue that the relentless connection to the Net leads to a new solitude and lack of human intimacy (Turkle, 2015 and 2011). It is now up to my students and their 90s generation to define human relationships for themselves. The use of PARO has helped me direct that discussion. Our robot encourages authentic communication in the classroom as we explore together autonomous humanoid robotics and the endless business applications.

\section{Outcomes}

My use of an autonomous humanoid interactive robot as a pedagogical tool in the classroom has achieved the following outcomes:

- to get students excited about growth and innovation in business today,

- to demonstrate how business and science are linked in real time,

- to explore the cutting-edge of interactive robotics technology, and

- to appreciate the implications of robotic technology on our (future) well-being, including enhanced interpersonal communication. 
PARO also allows me to prioritize the teaching of humans over the teaching of machines. Unfortunately, the latter is more common place today given the infatuation with computational software and online teaching at colleges and universities. Using an autonomous humanoid robot in the classroom helps educators refocus our attention on student learning, not the eye-catching educational software of the day. Why not focus our attention more fully on the silent transformation that is taking place, specifically, the slow acculturation of humans to living with humanoids? After all, how many people now go to sleep with their mobile device(s) on the bed stand? The separation between humans and our technologies is getting harder to imagine.

Using PARO in the classroom prompts me further to consider what teaching will be like in the near future when students bring their autonomous humanoid robots to class. How will educators adapt? Will it be permitted? Will robots be allowed to raise their mechanical hands to ask or answer a question? Will the human-humanoid duo take tests together? PARO also raises profound societal questions to consider with students. Should machines be allowed to have full autonomy in the world? Is an autonomous humanoid robot a person? If a machine can think, how do we know if it is not human? Can humans have real relationships with machines? Where do we draw the line between the human and the humanoid?

PARO has been a game-changer in my business classroom. Students tell me how excited they are to tell their parents and siblings that they met a robot today in class. One students said, "I feel as if I have seen the future!" That's engaged learning.

Soon everyone will have an interactive autonomous humanoid robot at home and on campus. Educators have a small window to take advantages of this quickly advancing technology and demonstrate how teachers find creative ways to integrate technology into the teaching-learning space to leverage learning and critical thinking. Most of the future belongs to the young. It is up to the old to impart our past to help students negotiate their futures.

\section{Acknowledgments}

My thanks to three humans who made this research on humanoids possible. First, my brother Jonn Flynn who introduced me to PARO and the scientific research on autonomous humanoid robots. Second, Dr. David Rehm, Provost at Mount St. Mary's University, who listened to my initial proposal, took me seriously, and risked co-funding the project. Third, Dr. Karl Einolf, Dean of the Mount's Richard J. Bolte, Sr. School of Business, who believed in my abilities to leverage learning in the classroom with a futuristic robot and offered matching grant funds. Thanks to all of you for helping me see the future more clearly!

\section{References}

Brynjolfsson, E., \& Andrew, M. (2014). The Second Machine Age: Work, Progress, and Prosperity in a Time of Brilliant Technologies. W.W. Norton.

Council of Independent Colleges. (2015, Fall). "Using an Autonomous Humanoid Robot in the Liberal Arts Classroom (feat. Dr. Patrice Flynn).” The Independent. Washington, DC.

Johnson, S. (2015, October 24). "Of Machines and Man.” Chicago Humanities Festival.

Robertson, J. (2013, November 26). "Robot Caregivers and Robo-therapy in Japan: Treating the "Trauma of Aging.'." University of Santa Barbara Lecture Series.

Scholl, C. (2014, March 3). "US Army to Replace Human Soldiers with 'Humanoid 
Robots'." Global Research News.

Sherry, T. (2011). Alone Together: Why We Expect More from Technology and Less from Each Other. NY: Basic Books.

The Economist. (2016, June 25). Special Report on Artificial Intelligence: The Return of the Machinery Question.

The Economist. (2014, March 29). Special Report on Robots: Immigrants from the Future.

Turkle, Sherry. (2015). Reclaiming Conversation: The Power of Talk in the Digital Age. New York: Penguin Press.

\section{Appendix 1. Robot Specifications}

Robot: $\quad$ PARO Therapeutic Robot ${ }^{\mathrm{TM}} 8^{\text {th }}$ generation design

$$
\text { Registered trademark of Intelligent System Co. Ltd, Japan }
$$

Manufacturer: Japan's National Institute of Advanced Industrial Science and Technology

License: Danish Technological Institute

Distributor: $\quad$ Beziehungen pflegen GmbH in Seeize, Germany

Cost: $\quad \$ 6,000$ (includes shipping and handling) $+\$ 840$ three-year warranty

Programmer: $\quad$ Patrice Flynn, $\mathrm{PhD}$

Professor of Business and Economics

Morrison Professor of International Studies

Richard J. Bolte, Sr. School of Business

Mount St. Mary's University

16300 Old Emmitsburg Road, Emmitsburg, MD 21727 USA

pflynn@msmary.edu

\section{Copyright Disclaimer}

Copyright for this article is retained by the author(s), with first publication rights granted to the journal.

This is an open-access article distributed under the terms and conditions of the Creative Commons Attribution license (http://creativecommons.org/licenses/by/3.0/). 